\title{
Materiais educativos em museus: investigando as possibilidades de desenvolvimento de experiências memoráveis
}

\author{
Luiza Novaes \\ PUC - Rio \\ Rosana Ferreira Alexandre \\ PUC - Rio
}

\begin{abstract}
Resumo
Este artigo apresenta uma investigação sobre materiais educativos voltados para crianças e publicados por museus. A partir de pesquisa documental, os materiais foram mapeados e analisados com o intuito de se perceber as experiências que proporcionam. As considerações demonstram que o conteúdo das publicações pode se libertar do compromisso puramente informativo e, com o auxílio do design, buscar uma aproximação de cunho mais emocional que possibilite experiências memoráveis entre o público, o espaço e o acervo.
\end{abstract}

Palavras-chave: museu, experiência memorável, material educativo

\begin{abstract}
This article presents an investigation of children's educational materials published by museums. Using documental research, the materials were mapped and analyzed in order to observe the experiences they provide. The considerations on the analysis show that the content of publications may become free of the commitment to be purely informative, and, with the help of design, seek a more emotional closeness that will enable memorable experiences to occur between the public, the space and the collection.
\end{abstract}

Keywords: museum, memorable experience, educational material

\section{INTRODUÇÃO}

A criança é o futuro, diz a sabedoria popular. Na literatura mais recente relativa à educação infantil (Sarmento, 2002), a infância é entendida como uma fase da vida com características próprias, na qual a criança é um ser completo e deve ser compreendida como tal, não apenas como o que ela virá a ser. Para os museus, a criança representa tanto o futuro, afinal conquistar os mais novos pode significar a formação de um público apreciador dessas instituições quando adulto, quanto o presente, uma vez que é frequente a visitação de crianças principalmente dentro do âmbito escolar (Cazelli, 2005; Carvalho, 2011). Cientes disto, os museus trabalham para melhor recepcionar o 
público infantil. Mas esse é um longo percurso, com muitos desafios, e que exige constante adaptação. Estamos no caminho correto?

A passagem do museu de um espaço restritivo, fechado, para poucos, para a visão contemporânea de instituição cultural aberta e articulada com a sociedade, traz consigo uma série de questionamentos. No contexto desta comunicação, interessa-nos sobretudo os novos horizontes que a instituição vem delimitando para acolher o público infantil e as possibilidades para desenvolver experiências, particularmente por meio de publicações produzidas pelos próprios museus. É nesse sentido que buscamos indagar o papel do design junto a esses objetos de mediação.

Abordamos o design nessa comunicação não apenas em relação às suas características materiais ou seus projetos gráficos, mas também em relação ao aspecto da experiência que oferecem. Temos como pressuposto que esses objetos são ferramentas que proporcionam momentos de interação com o público, momentos pessoais e memoráveis. Aqui podemos traçar um paralelo com o que Buchanan denomina de "terceira área do design". ${ }^{1}$ Para o autor, o aspecto mais interessante deste âmbito é a interação, seja ela de qualquer ordem, entre pessoas com outras pessoas, ou entre pessoas e objetos, ou seja, o design como projeto de processos e atividades, como planejamento de relações ou coisas que apoiem esta interação. (Buchanan, 2013)

Partindo dessas premissas, visamos com esta pesquisa: (1) Levantar e mapear publicações destinadas ao público infantil produzidas e editadas por museus; (2) Organizar categorias de materiais educativos museais de acordo com sua abordagem e relacionar com o desenvolvimento de experiências; (3) Analisar o papel do design junto ao museu, especificamente em relação aos materiais educativos, como mediador entre o público e o acervo deste e, a possível contribuição para se criar experiências museais memoráveis. Ressaltamos que o intuito da pesquisa centra-se mais na identificação e análise dos tipos de material do que na quantificação dos mesmos.

A título de esclarecimento, neste artigo utilizamos os termos catálogo, cartilha e publicação como sinônimos para materiais educativos produzidos pelos museus, uma vez que não há um consenso de terminologia a ser usada. Percebemos que esta varia de acordo com o museu pesquisado.

\footnotetext{
${ }^{1}$ Segundo o autor, a comunicação visual seria a primeira área do design; a seguinte seria a produção de objetos; a terceira tem em conta processos e atividades; e ainda teria uma quarta associada a sistemas e ambientes. (Buchanan, 1995, p. 9-10)
} 


\section{A INTERNET: COMO SEI PARA ONDE VOU?}

Pense na visita. Quando vamos a algum lugar, precisamos de referências. Estamos na era digital, e o caminho que geralmente recorremos é pesquisar na internet. Não se engane, mesmo crianças, ou especialmente elas, já estão familiarizadas com a tecnologia, e não seria surpresa ver um pai a procura de informações na internet juntos com seus filhos antes de levá-los ao museu. Há casos inclusive das crianças pedirem para ver o site do museu antes de escolher qual querem conhecer presencialmente. ${ }^{2}$

São muitos os museus, com seus acervos variados e espalhados ao redor do mundo, que estão no mundo digital, seja com o intuito de disponibilizar informações, divulgar eventos ou até mesmo oferecer seus produtos para venda. $\mathrm{O}$ acesso virtual pode influenciar tanto na escolha do espaço a ser visitado como para torná-lo mais interessante, já que possibilita a familiarização do público com os acervos das instituições. E o público não deixa a desejar. Em 2014, a National Gallery on-line recebeu seis milhões de visitas e o site do Metropolitan mais de 26 milhões. ${ }^{3}$

Iniciamos a pesquisa pensando no que os museus disponibilizam para as crianças na internet. Antes de tudo, porém, fizemos uma seleção das instituições para ter um direcionamento. O critério adotado foi buscar primeiro por instituições de renome internacional, e para isso seguimos a pesquisa realizada pelo Themed Entertainment Association (TEA), reconhecida organização internacional que lista anualmente as instituições de excelência. Buscamos dados das últimas duas pesquisas, a de $2013^{4}$ relativa à visitação em museus em 2012 , e a de $2014^{5}$ que traz as instituições mais visitadas em 2013. O interesse foi buscar referências entre os museus que já tivessem seus nomes estabelecidos, com algum sucesso, sem questionar qual entre eles era o melhor. A partir desses dados construímos as tabelas abaixo com os 10 museus mais visitados nesses respectivos anos:

\footnotetext{
${ }^{2}$ Depoimento de André Ramos durante aula "Desenvolvimento da Tese" ministrada por Rita Couto e Luiza Novaes no âmbito do doutorado em design na Puc-Rio em 2014.

${ }^{3}$ Disponível em: http:/g1.globo.com/turismo-e-viagem/noticia/2015/03/grandes-museus-do-mundo-se-adaptam-paralidar-com-multidoes.html. Acesso em: 23/03/2015.

${ }^{4}$ Disponível em: http://www.aecom.com/deployedfiles/Internet/Capabilities/Economics/_documents/ThemeMuseum Index 2013.pdf. Acesso em: 06/12/2013

${ }^{5}$ Disponível em: http://www.aecom.com/deployedfiles/Internet/Capabilities/Economics/_documents/2012\%20Theme \%20Index\%20Combined_1-1_online.pdf. Acesso em: 13/04/2015.
} 
10 museus mais visitados no mundo em 2012

\begin{tabular}{|l|l|l|}
\hline Museu & Materiais on-line & País \\
\hline Musée du Louvre & $\mathrm{x}$ & França \\
\hline $\begin{array}{l}\text { National Museum of } \\
\text { Natural History }\end{array}$ & & EUA \\
\hline $\begin{array}{l}\text { Smithsonian National } \\
\text { Air and Space } \\
\text { Museum }\end{array}$ & $\mathrm{x}$ & EUA \\
\hline $\begin{array}{l}\text { The Metropolitan } \\
\text { Museum of Art }\end{array}$ & $\mathrm{x}$ & EUA \\
\hline British Museum & & Inglaterra \\
\hline Tate Modern & $\mathrm{x}$ & Inglaterra \\
\hline The National Gallery & $\mathrm{x}$ & Inglaterra \\
\hline Vatican Museums & & Itália \\
\hline $\begin{array}{l}\text { American Museum of } \\
\text { Natural History }\end{array}$ & & EUA \\
\hline $\begin{array}{l}\text { Natural History } \\
\text { Museum }\end{array}$ & $\mathrm{x}$ & Inglaterra \\
\hline
\end{tabular}

Top 10 museus mais visitados no mundo em 2013

\begin{tabular}{|l|l|l|}
\hline Museus & Materiais on-line & País \\
\hline Musée du Louvre & $\mathrm{x}$ & França \\
\hline $\begin{array}{l}\text { National Museum of } \\
\text { Natural History }\end{array}$ & & EUA \\
\hline $\begin{array}{l}\text { National Museum of } \\
\text { China }\end{array}$ & $\mathrm{x}$ & China \\
\hline $\begin{array}{l}\text { Smithsonian National } \\
\text { Air and Space } \\
\text { Museum }\end{array}$ & $\mathrm{x}$ & EUA \\
\hline British Museum & & Inglaterra \\
\hline $\begin{array}{l}\text { The Metropolitan } \\
\text { Museum of Art }\end{array}$ & $\mathrm{x}$ & EUA \\
\hline The National Gallery & $\mathrm{x}$ & Inglaterra \\
\hline Vatican Museums & $\mathrm{x}$ & Itália \\
\hline $\begin{array}{l}\text { Natural History } \\
\text { Museum }\end{array}$ & $\mathrm{Inglaterra}$ \\
\hline $\begin{array}{l}\text { American Museum of } \\
\text { Natural History }\end{array}$ & & EUA \\
\hline
\end{tabular}

A partir desse levantamento, percebemos que em 2012 dos 10 museus mais visitados seis eram europeus, destes, quatro dispõem de materiais on-line. Em 2013, com a entrada de um museu asiático no ranking, a Europa fica com a metade dos museus mais visitados, dentre os quais três têm publicações na internet. O curioso é que nove museus aparecem na lista dos museus mais visitados em dois anos consecutivos, apenas tendo suas posições levemente alteradas na lista. 
Em seguida, tentamos seguir o mesmo procedimento metodológico com as instituições brasileiras. $\mathrm{Na}$ falta de estudos no país que indicassem os museus mais visitados, fizemos um recorte através do seguinte critério: a partir de uma pesquisa no Google achamos uma lista com os 29 melhores museus do país em pesquisa realizada pelo Guia Quatro Rodas ${ }^{6}$ em 2013, e outra, com os dez museus mais visitados do estado de São Paulo ${ }^{7}$ em 2014. Abaixo segue a tabela produzida a partir da primeira referência, que diz respeito às dez melhores instituições para se visitar no país.

10 melhores museus brasileiros 2013

\begin{tabular}{|l|l|l|}
\hline Museus & Materiais on-line & Estado \\
\hline Catavento Cultural & & SP \\
\hline $\begin{array}{l}\text { Museu da Língua } \\
\text { Portuguesa }\end{array}$ & SP \\
\hline $\begin{array}{l}\text { Museu de Arte de São } \\
\text { Paulo (MASP) }\end{array}$ & SP \\
\hline $\begin{array}{l}\text { Museu de Ciência e } \\
\text { Tecnologia (PUC) }\end{array}$ & RS \\
\hline Museu do Futebol & & SP \\
\hline Museu Imperial & $\mathrm{x}$ & $\mathrm{RJ}$ \\
\hline Instituto Inhotim & & MG \\
\hline $\begin{array}{l}\text { Pinacoteca do estado } \\
\text { de São Paulo }\end{array}$ & & SP \\
\hline $\begin{array}{l}\text { Museu da Gente } \\
\text { Sergipana }\end{array}$ & $\mathrm{x}$ & $\mathrm{SE}$ \\
\hline $\begin{array}{l}\text { Museu de Artes e } \\
\text { Ofícios }\end{array}$ & & MG \\
\hline
\end{tabular}

Em relação à segunda referência, os dez museus paulistanos que tiveram mais público em 2014, optamos por apenas listar as instituições, uma vez que nenhuma delas disponibiliza materiais on-line para as crianças. Começamos a enumerar das mais visitadas para as menos, sendo elas: Museu da Imagem e do Som; Catavento Cultural; Pinacoteca; Museu do Futebol; Museu da Língua Portuguesa; Museu de Arte de São Paulo; Museu Afro Brasil; Museu da Casa Brasileira; Casa das Rosas; Museu da Imigração.

Por essas referências, percebe-se que os museus brasileiros quase não oferecem materiais on-line para crianças, uma vez que apenas duas instituições têm esse tipo de

\footnotetext{
${ }^{6}$ Publicado pela revista Viaje Aqui. Disponível em: http://viajeaqui.abril.com.br/materias/melhores-museus-dobrasil-guia-brasil\#10. Acesso em: 23/05/2015. O Guia Quatro Rodas é uma publicação da Editora Abril que conta com a avaliação de repórteres, que visitam os lugares como turistas, para listar as atrações por ordem de estrelas. Disponível em: http://viajeaqui.abril.com.br/materias/como-o-guia-quatro-rodas-classifica-as-atracoes-no-brasil. Acesso em: 25/05/2015.

${ }^{7}$ Levantamento realizado pelo Observatório de Turismo e Eventos, núcleo de estudos e pesquisas da SPTuris. Disponível em: http://opiniao.estadao.com.br/noticias/geral,museus-em-alta-imp-,1676174. Acesso em: 23/05/2015.
} 
material. É de se destacar que dentre os dez melhores museus, a grande maioria está localizada na região sudeste, sendo que cinco concentram-se no estado de São Paulo, e nenhum deles tem catálogos on-line destinado ao público infantil.

Com estes poucos dados em mãos, decidimos alterar a estratégia metodológica. A fim de conseguir mais material para análise relativo aos museus brasileiros, buscamos nominalmente instituições que sabíamos que disponibilizavam estas publicações, o que nos possibilitou encontrar catálogos em mais oito instituições.

Com o propósito de conseguir ainda mais materiais, até para conhecer o que se disponibiliza para as crianças na área museológica, achamos que seria interessante fazer uma pesquisa com palavras-chave no Google. Assim tivemos acesso a materiais de mais dez museus, nacionais e internacionais.

\section{COMO MAPEAR?}

Após a fase de busca e coleta dos materiais, seguimos para a etapa seguinte que constituiu-se na tentativa de organização e classificação dos mesmos. Ao manipulá-los, percebemos que, embora tenham o mesmo objetivo - aproximar o museu das crianças existem abordagens variadas: publicações próprias para serem lidas antes de se visitar as instituições, livros/cartilhas para acompanhar as crianças durante a visita e outras destinadas para depois de terem percorrido os museus. Existem materiais que mesclam mais de uma dessas abordagens e os que têm o intuito de estimular o interesse sobre uma exposição ou museu sem estar relacionados diretamente à visita do mesmo. A seguir segue uma tabela que enumera os museus pesquisados com os tipos de materiais que disponibilizam na internet: 
Relação por tipo de materiais disponibilizado na internet

\begin{tabular}{|c|c|c|c|c|c|c|c|}
\hline Museu & (A) & (ADP) & (AP) & (D) & (DP) & (P) & (L) \\
\hline Ashmolean Museum & & & & $\mathrm{x}$ & $\mathrm{x}$ & & \\
\hline Centro Cultural do Banco do Brasil & & & & & & & $\mathrm{x}$ \\
\hline Imperial War Museums & & & & $\mathrm{x}$ & & $\mathrm{x}$ & \\
\hline Manchester Museum & & & $\mathrm{x}$ & & & & \\
\hline Musée du Louvre & & & & $\mathrm{x}$ & & & \\
\hline Museu da Gente Sergipana & $x$ & & & & & & \\
\hline Museu da República & & & & & & & $\mathrm{x}$ \\
\hline Museu da Vida & & & & & & & $\mathrm{x}$ \\
\hline Museu de Valores do Banco Central & & & $\mathrm{x}$ & & & & \\
\hline Museu Imperial & & & $\mathrm{x}$ & & & & \\
\hline Museu Municipal de Penafiel & & & & & & & $\mathrm{x}$ \\
\hline Museu Nacional de Soares dos Reis & & & & $\mathrm{x}$ & & & \\
\hline Museu Nacional/UFRJ & & & & $\mathrm{x}$ & $\mathrm{x}$ & & \\
\hline Museu Oscar Niemeyer & $\mathrm{x}$ & & & & & & \\
\hline Museu Paraense Emílio Goeldi & & & & & & & $\mathrm{x}$ \\
\hline Museums Sheffield & & & & $\mathrm{x}$ & & & \\
\hline National Gallery of Art & & & & $x$ & & & \\
\hline National Museum of Ireland & & & & $\mathrm{x}$ & & $\mathrm{x}$ & \\
\hline Natural History Museum & & $\mathrm{x}$ & & $\mathrm{x}$ & & & \\
\hline $\begin{array}{l}\text { Smithsonian National Air and Space } \\
\text { Museum }\end{array}$ & & & & $\mathrm{x}$ & & & \\
\hline Tate Modern & & & $\mathrm{x}$ & & & & \\
\hline The Metropolitan Museum of Art & & & $x$ & $\mathrm{x}$ & $\mathrm{x}$ & & \\
\hline The National Gallery & & & & $\mathrm{x}$ & & & \\
\hline Victoria and Albert Museum & & & & $x$ & & & \\
\hline
\end{tabular}

Legenda dos materiais de acordo com a abordagem do momento da visita a que se destina : (A) - Antes / (ADP) - Antes, durante e pós / (AP) - antes e pós / (D) - Durante / (DP) - Durante e pós / (L) - Livro / (P) - Pós visita

Observa-se que no total de 24 museus pesquisados, a maior parte deles (14) tem materiais para auxiliar as crianças no momento em que elas estão no museu. Em seguida, estão as cartilhas para antes e/ou depois da visita presentes em quatro instituições. As cartilhas específicas para estimular a ida ao museu não são muito frequentes, aparecendo apenas em dois museus, assim como as específicas para o público infantil que já tenha percorrido as galerias, e mais incomum ainda é a publicação que une os três momentos da visita, o anterior, o durante e o posterior, que aparece em apenas um museu da nossa amostragem.

Especificamente sobre os museus brasileiros, percebe-se que os materiais mais comuns são os livros (4), seguidos de cartilhas para antes da visita (2) ou antes/depois, disponível também em dois museus. Vale ressaltar que, ao contrário do que acontece no panorama internacional, publicação que acompanha o percurso da criança na exposição só foi encontrada em uma instituição. 


\section{PERCORRENDO AS CATEGORIAS: QUE EXPERIÊNCIAS DESPERTAR?}

Diante do levantamento e da categorização dos materiais, passamos para a etapa de análise dos mesmos, lançando um olhar crítico e estabelecendo um paralelo entre os materiais e as experiências possíveis, em cada abordagem, seja pelo olhar do design, como da filosofia e da educação.

De acordo com os exemplos recolhidos, os materiais que antecipam o contato das crianças com as mostras expositivas têm em comum o fato de apresentarem descritivamente o museu ao mesmo tempo em que convidam o público a visitar o mesmo presencialmente. Curiosamente, os dois exemplos coletados usam a linguagem das histórias em quadrinhos para dialogar com as crianças e em um deles encontramos atividades lúdicas sobre a instituição.

Se a linguagem visual é pensada para se aproximar das crianças, o mesmo não podemos dizer do conteúdo veiculado. Nessa mesma publicação que propõe o uso de brincadeiras, percebemos uma preocupação em esclarecer regras de comportamento para as crianças, quase como um protocolo de visita ao museu (figura 1). O outro exemplo mostra-se mais preocupado em ressaltar os ambientes agradáveis que o museu disponibiliza (figura 2). Em ambos, o foco parece estar no museu e não na criança uma vez que a informação sobre a instituição é o destaque.
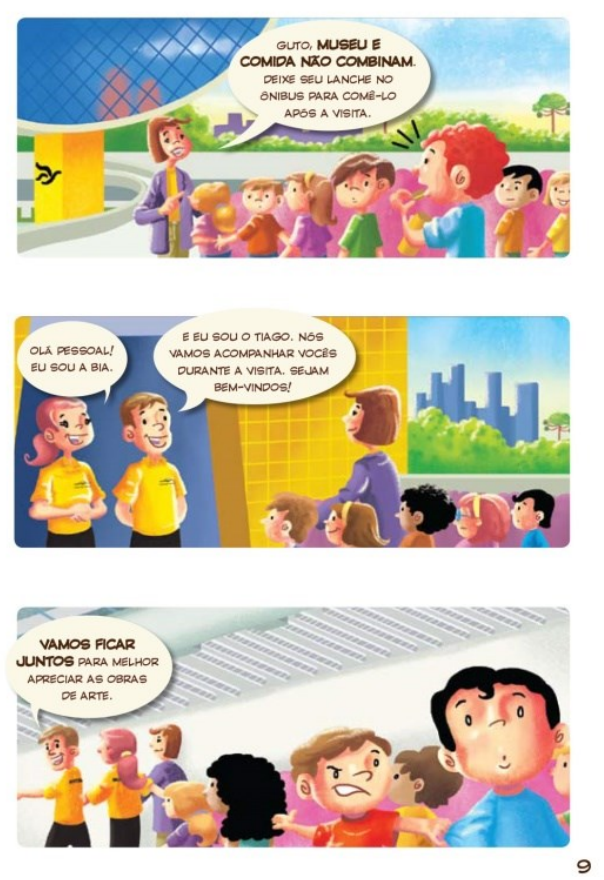

Figura 1: Material do Museu Oscar Niemeyer (Brasil) ${ }^{8}$

\footnotetext{
${ }^{8}$ Disponível em: http://www.museuoscarniemeyer.org.br/mon/pdf/uma_visita_mon.pdf. Acesso em: 12/08/2015.
} 

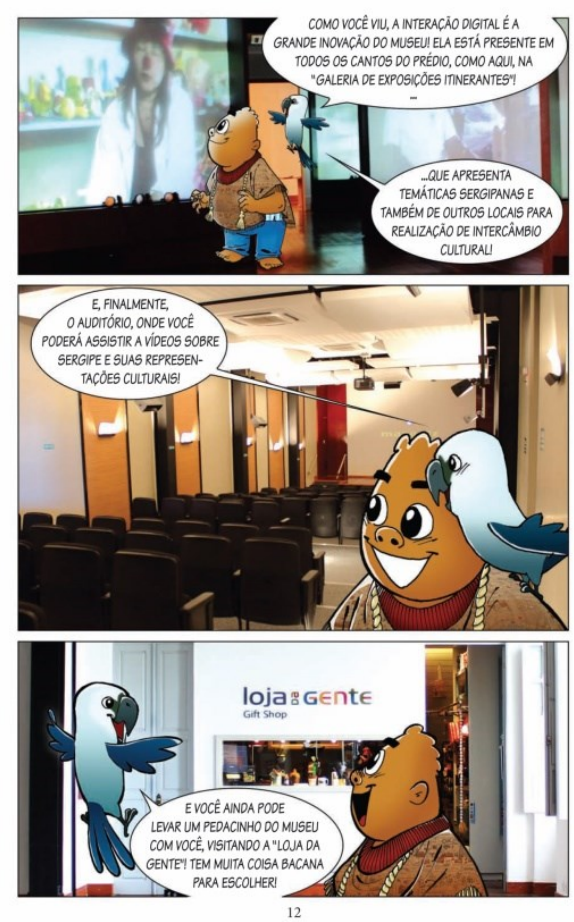

Figura 2: Material do Museu da Gente Sergipana (Brasil) ${ }^{9}$

A segunda categoria, identificada por materiais que estimulam tanto o antes, o durante como o depois da visita só foi encontrada em um museu de nossa amostragem. Nesta publicação, o conteúdo das exposições é explorado por meio de atividades lúdicas. As crianças são instigadas a pensar sobre o que vão ver e a selecionarem informações personalizadas, deixando-as escolher o que querem destacar. Em uma das seções do material, pede-se que as crianças reescrevam as etiquetas da exposição pensando em uma informação mais atraente para as crianças menores. O público infantil é convidado a destacar o que lhe parece mais importante, reelaborar o conteúdo e montar uma exibição, entendendo como funciona um museu na prática (figura 3).

\footnotetext{
${ }^{9}$ Disponível em: http://www.museudagentesergipana.com.br/wps/portal/inicial/projetos/revistaemquadrinhos. Acesso em: $12 / 08 / 2015$.
} 


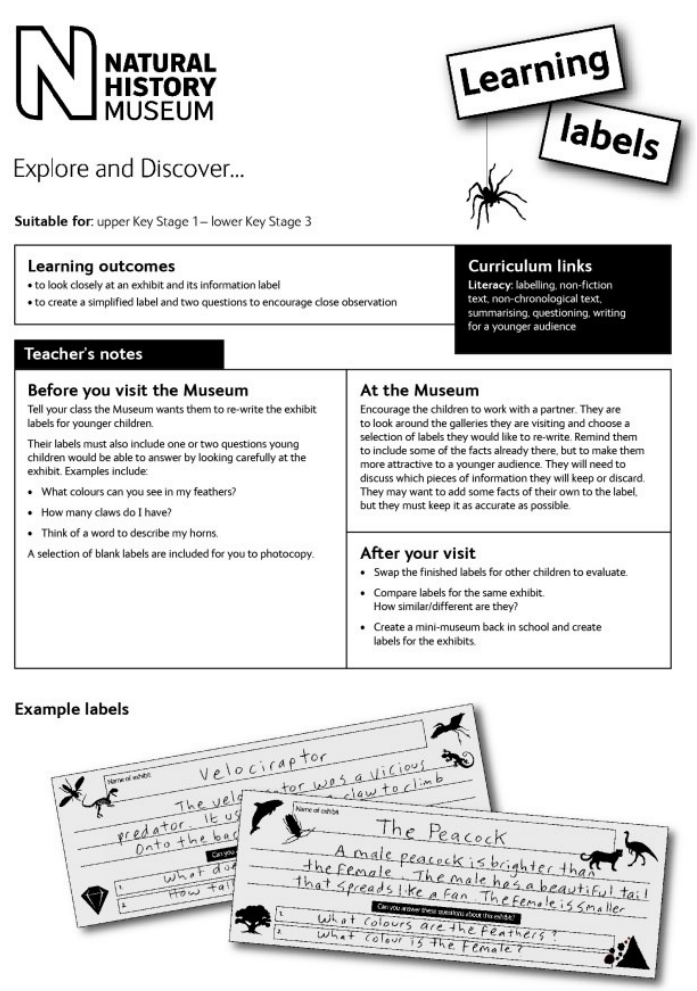

Figura 3: Material do Natural History Museum (Inglaterra) ${ }^{10}$

De todas as categorias analisadas, esta foi a que apresentou mais brechas para que as crianças estabelecessem suas relações e desenvolvessem sua criatividade ao mesmo tempo em que permitiam ao público produzir experiências significativas. Com questões em aberto, mas relacionadas ao museu, os visitantes são estimulados a extrair da exposição fatos de seu interesse. Dewey (1976), ao falar sobre experiência, de certa forma salienta esses pontos. O pedagogo americano, ao diferenciar a educação tradicional da progressiva, propõe que se dê mais voz para os estudantes. Para ele, ao invés da escola se focar em ensinar assuntos particulares, o ideal é que ela se importe mais com a “(...) formação de atitude de gostos e desgostos (...) pois " a mais importante atitude a ser formada é a do desejo de continuar a aprender" (p. 42). O Natural History Museum parece ter esse entendimento em vista.

O terceiro grupo, aqui denominado como materiais para antes/depois da visita, reúne uma série de publicações, algumas se concentrando em mostrar curiosidades sobre o museu, como é o caso do Metropolitan, que esclarece o que acontece nas segundas-feiras, dia em que está fechado para o público. Outras tentam utilizar o acervo de forma lúdica, como é o caso da Tate, que propõe uma espécie de ficha para ressaltar o trabalho de um artista ao mesmo tempo em que ensina as crianças a fazerem sua

\footnotetext{
${ }^{10}$ Disponível em: http://www.nhm.ac.uk/resources-rx/files/learning_labels-14393.pdf. Acesso em: 12/08/2015.
} 
própria versão da obra, a partir de materiais acessíveis como papéis, tintas, massa de modelar e brinquedos (figura 4). Há, entretanto, casos em que o conteúdo transmitido relaciona-se com a temática do museu, mas não necessariamente a uma exposição específica, como acontece nas publicações do Museu Imperial e do Museu de Valores do Banco Central. Enquanto o primeiro retoma a história do Palácio que abriga a instituição assim como os costumes da época num material com 60 páginas, o segundo busca informar as crianças como é fabricado o dinheiro ou o que fazer para poupá-lo, a partir de uma história em quadrinhos.

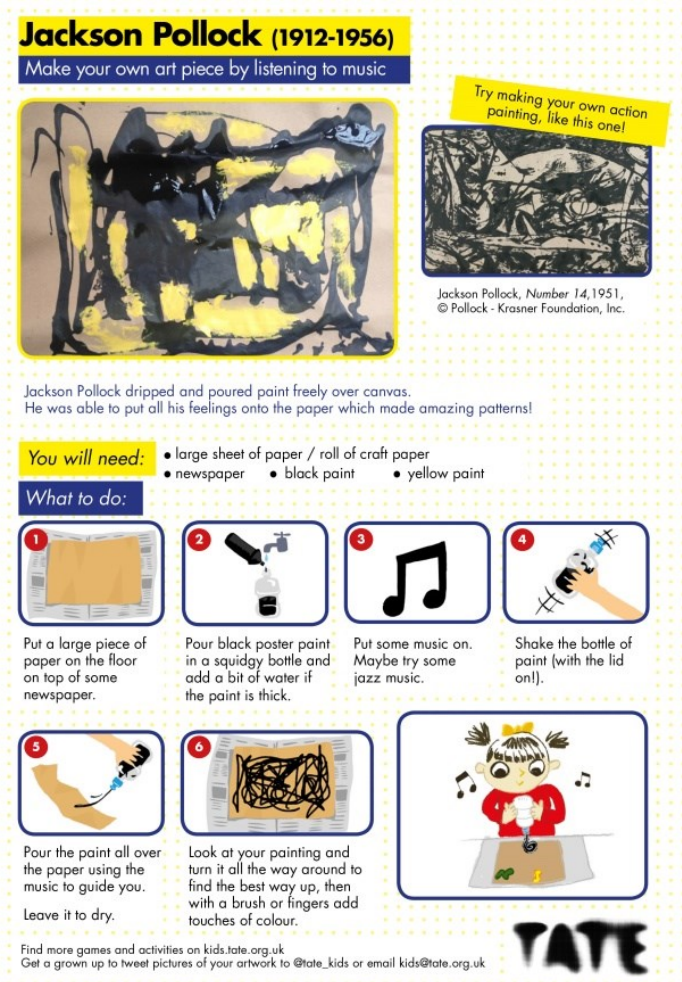

Figura 4: Material da Tate Modern (Inglaterra $)^{11}$

Em seguida temos a categoria de materiais que mais exemplos encontramos, as cartilhas que conduzem as crianças pelas salas dos museus. Normalmente acompanhados de um mapa das galerias, estes materiais tentam direcionar e localizar o público perante seus espaços. Tendem a ressaltar objetos da coleção para serem vistos em detalhes, pedindo para que as crianças descubram artefatos com determinadas características, desenhem algum objeto, preencham textos informativos com lacunas, respondam questões de múltipla escolha ou participem de jogos e brincadeiras com informações das peças a serem pesquisadas.

\footnotetext{
${ }^{11}$ Disponível em: http://kids.tate.org.uk/pdf/Jazzy-Drips.pdf. Acesso em: 12/08/2015.
} 


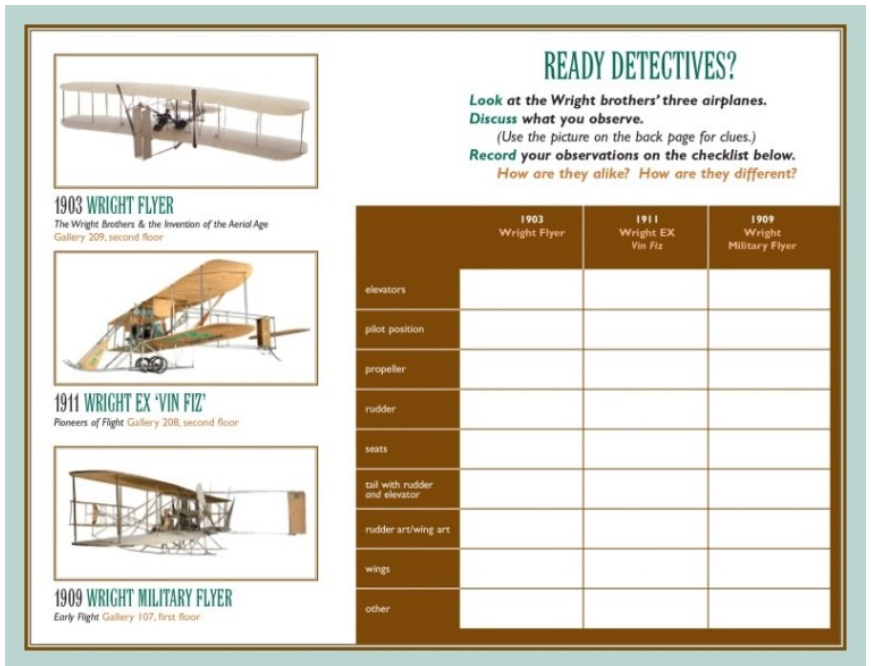

Figura 5: Material do Smithsonian National Air and Space Museum (Estados Unidos) ${ }^{12}$

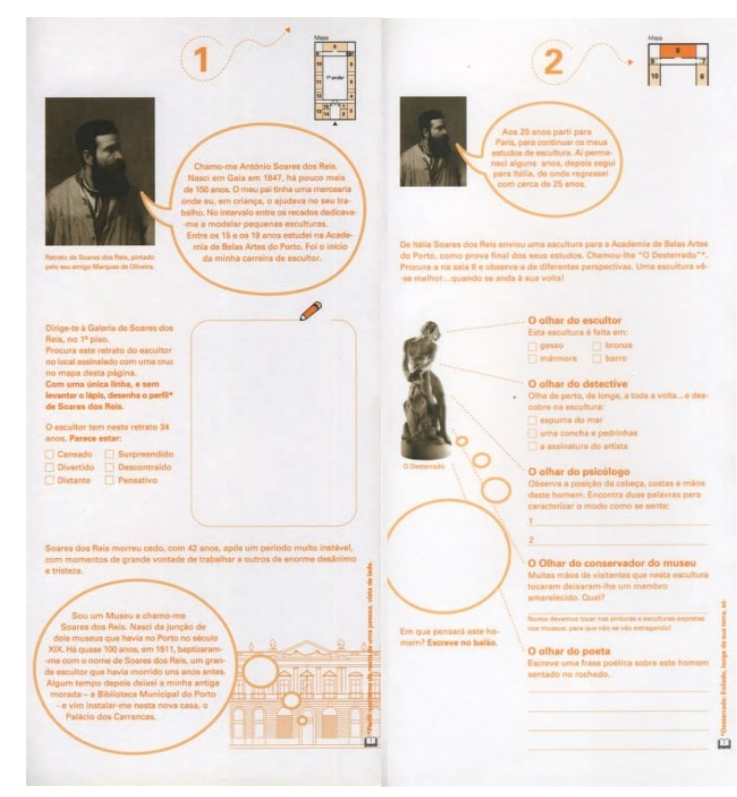

Figura 6: Material do Museu Nacional de Soares dos Reis (Portugal) ${ }^{13}$

Em quase todos os casos há uma preocupação em envolver a criança, entretanto percebe-se que o espaço destinado a este público pode ser trabalhado de forma variada, às vezes mais atrelada ao conteúdo expositivo com dados a serem verificados (figuras 5 e 6), às vezes com mais espaço para criação de conteúdo pela própria criança (figura 7).

\footnotetext{
${ }^{12}$ Disponível em: http://airandspace.si.edu/exhibitions/wright-brothers/online/pdf/classAct/Wright_Brothers Flight_Path.pdf. Acesso em: 12/08/2015.

${ }^{13}$ Disponível em: http://www.museusoaresdosreis.pt/Data/Documents/bem_vindo.pdf. Acesso em: 12/08/2015.
} 


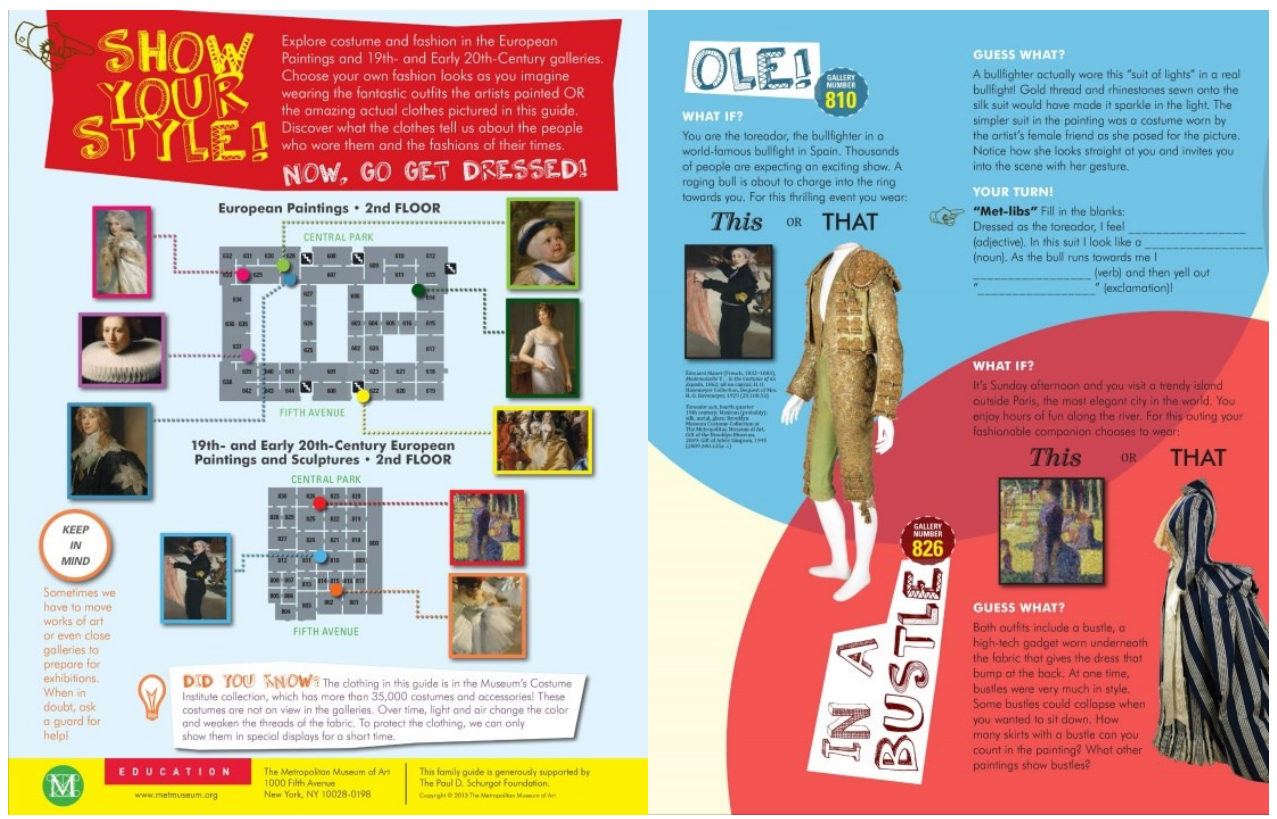

Figura 7: Material do Metropolitan Museum of Art (Estados Unidos) ${ }^{14}$

Não por acaso, recorremos agora a Walter Benjamin. Ao discorrer sobre o declínio da narrativa em "O Narrador” (1994), Benjamin trata sobre novas formas de comunicação, especificamente o romance e a informação jornalística. Se para o filósofo alemão a experiência está atrelada ao ato de contar histórias, como ato de transmissão de conhecimento, os novos tipos de divulgação não deixam margem para que se molde a experiência. Tanto o romance como a informação jornalística compreendem uma outra concepção de experiência, de leitura e entendimento rápido.

Cada manhã recebemos notícias de todo o mundo. E, no entanto, somos pobres em histórias surpreendentes. A razão é que os fatos já nos chegam acompanhados de explicações. Em outras palavras: quase nada do que acontece está a serviço da narrativa, e quase tudo está a serviço da informação. Metade da arte da narrativa está em evitar explicações. (Benjamin, 1994, p. 203)

Ainda segundo Benjamin, as histórias são tecidas pelas mãos do narrador, como um artesão que realiza o trabalho manual com a paciência que lhe é habitual. Quem as ouve, deve interpretá-las de acordo com a época e o contexto, deve ter calma para refletir, para que a experiência aconteça. Pois bem, observando as publicações, algumas parecem estar mais preocupadas em passar um conteúdo informativo, casos do Smithsonian's National Air and Space Museum e do Museu Soares dos Reis (figuras 5 e

\footnotetext{
${ }^{14}$ Disponível em: http://www.metmuseum.org/learn/for-kids/ /media/AA6C2E7CD29C441FA9EEF64185A74F1B. pdf. Acesso em: 12/08/2015
} 
6 respectivamente) do que incluir um espaço para a produção das crianças, como em um processo de coautoria.

Seguindo nosso mapeamento, as próximas publicações dizem respeito não só ao momento em si da visita como ao momento posterior desta. De maneira geral, essas publicações seguem as características dos materiais que auxiliam a visita. Como diferença percebe-se apenas a inclusão de atividades que necessitam de mais tempo para reflexão ou execução das mesmas (figura 8).

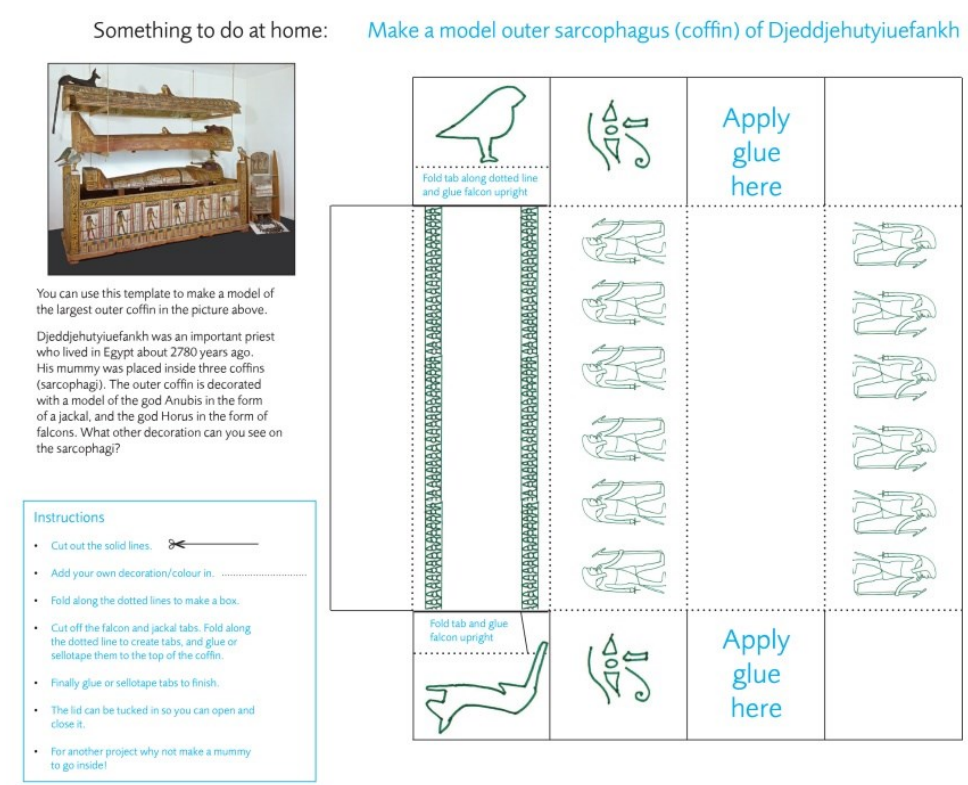

Figura 8: Material do Ashmolean Museum of Art and Archaelogy - University of Oxford (Inglaterra $)^{15}$

Já as cartilhas destinadas às crianças que já visitaram o museu, que na nossa pesquisa resumem-se a 2 casos, têm em comum o fato de proporem atividades. Enquanto o National Museum of Ireland propõe que o público infantil escolha um objeto de sua preferência e o descreva a partir de perguntas já feitas (figura 9), o Imperial War Museums explora assuntos de sua temática de forma lúdica (figura 10).

\footnotetext{
${ }^{15}$ Disponível em: http://www.ashmolean.org/education/resources/resources2011/AncientEgyptTrail.pdf. Acesso em: $12 / 08 / 2015$
} 


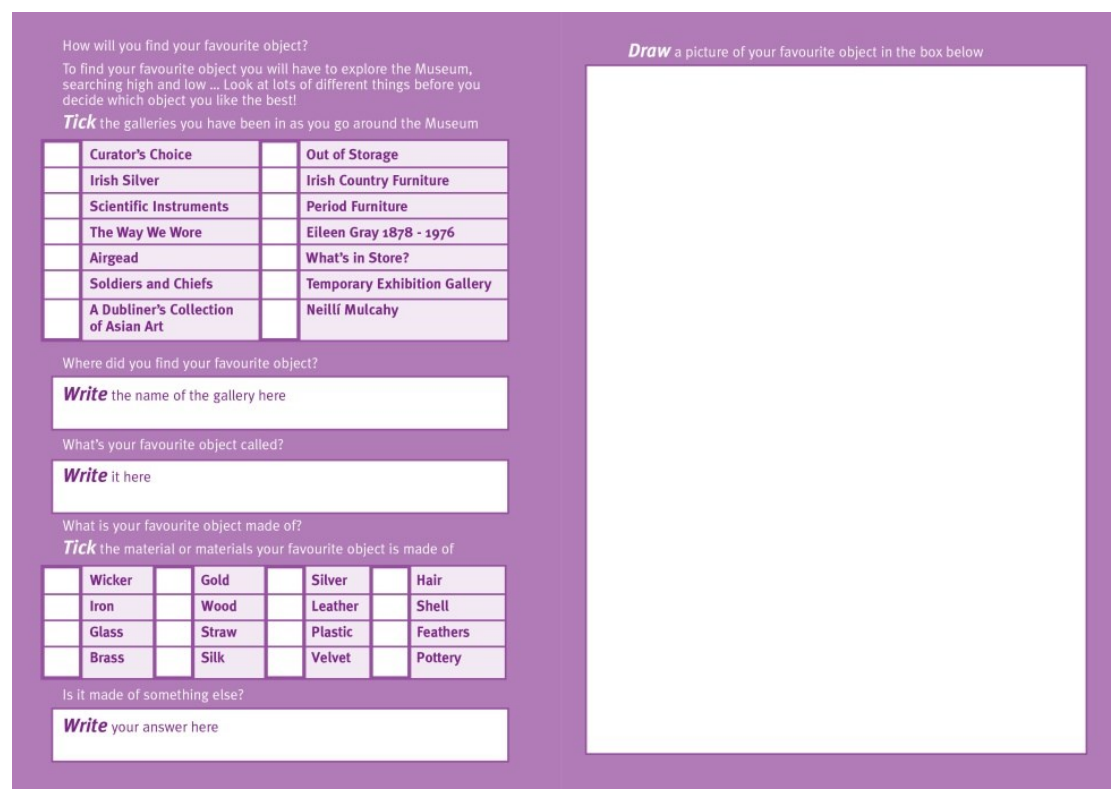

Figura 9: Material do National Museum of Ireland (Irlanda) ${ }^{16}$

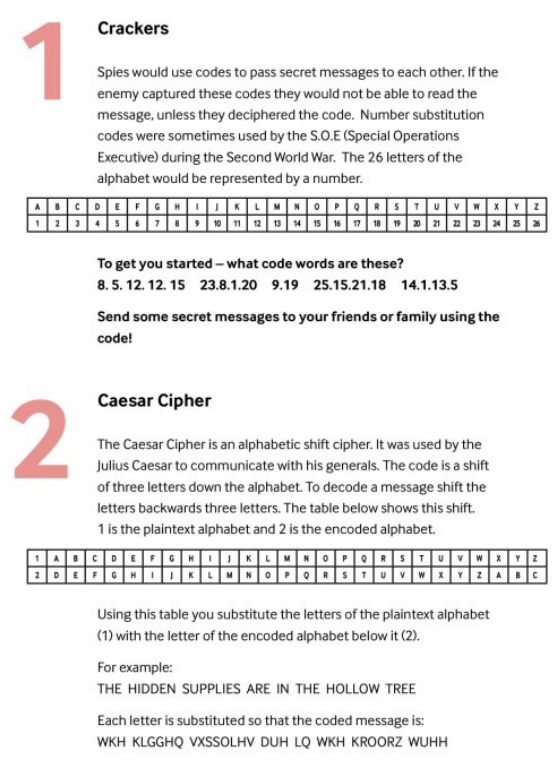

Figura 10: Material do Imperial War Museums (Inglaterra) ${ }^{17}$

Por fim, chegamos a um tipo de material que designamos como livros, uma vez que não está claro a que momento da visita eles se destinam. Em comum eles têm o intuito de estimular o interesse sobre uma exposição ou um museu, sem estar relacionados diretamente à visita do mesmo. Como um livro infantil, a maioria explora

\footnotetext{
16 Disponível em: http://www.museum.ie/en/list/families-children-decorative-arts-history.aspx?article=8cc9d530a897-4788-8a8a-906d18b98def. Acesso em: 12/08/2015.

${ }^{17}$ Disponível em: http://www.iwm.org.uk/sites/default/files/public-document/Secret\%20Activities.pdf. Acesso em: $12 / 08 / 2015$
} 
tanto a linguagem textual quanto a imagética e sua interligação (figura 11). Contam histórias sobre um personagem ou um assunto específico, é o caso do Museu da Vida, que revela o funcionamento do corpo humano, e do Centro Cultural Banco do Brasil, que remete à vida de Kandinsky.

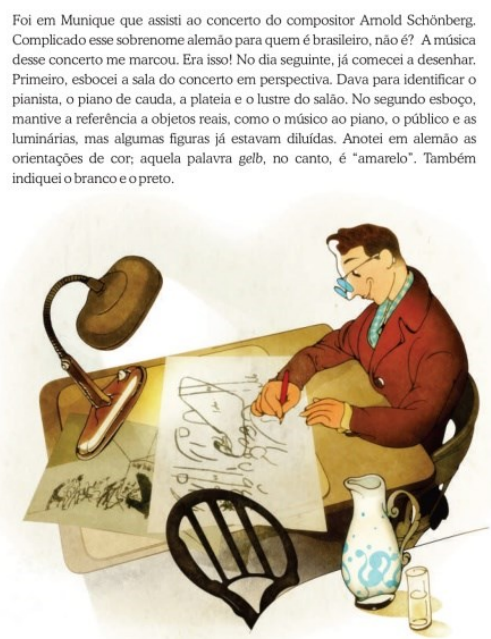

Figura 11: Material do Centro Cultural Banco do Brasil (Brasil) ${ }^{18}$

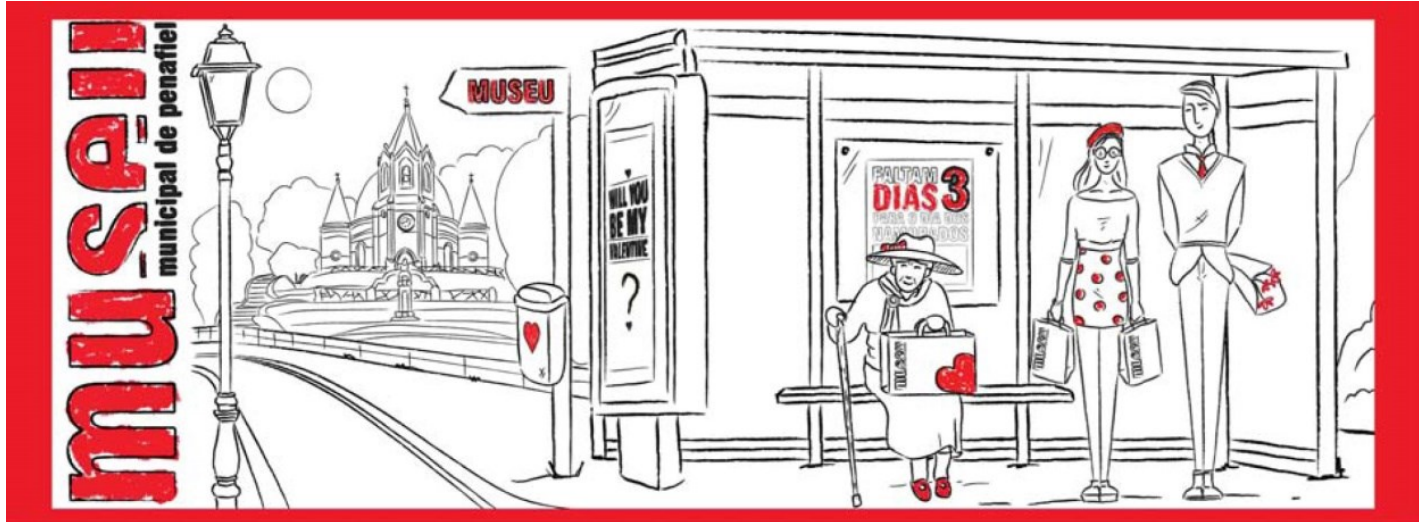

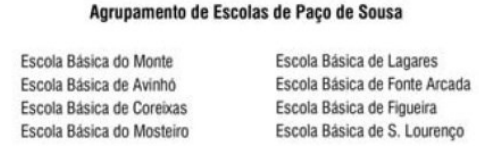

12 Unm Museu de Atetos
Numa serena tarde de primavera, os alunos do quarto ano foram visitar 0 Museu dos Afetos, localizado na linda cidade de Penafiel. Assim que chegaram, foram calorosamente recebidos por uma menina que entregou uma flor a cada aluno.

Entraram! Que encanto! As paredes estavam decoradas com rostos sorridentes: crianças, adultos e idosos. Tâo sorridentes eram estes rostos, que faziam rir qualquer pessoa. Continuaram o seu percurso a sorrir e toda a visita se tornou mais interessante.

- Que beleza! Como é boa a amizade! - diziam os alunos.

Figura 12: Material do Museu Municipal de Penafiel (Portugal) ${ }^{19}$ 
A análise desses materiais nos remeteu a estudos de Donald Norman (2004), nos quais trata do design emocional. Em sua pesquisa, Norman sugere que existem três níveis de estruturas no cérebro que interagem entre si: o nível visceral, o comportamental e o reflexivo. O primeiro estaria relacionado ao início do processo emocional e, portanto, está associado a respostas automáticas, que julgam rapidamente se algo é bom ou ruim, por exemplo; o segundo nível é responsável pela maior parte de nossas ações, pelas coisas que fazemos de forma inconsciente, como dirigir um carro; e finalmente o último estágio, intitulado reflexivo, é o nível da compreensão, contemplação e interpretação, onde as ações acabam sendo processadas. Seguindo essas diretrizes, Norman propõe que interpretemos nossa relação com objetos a partir dessas reações, que seriam os "três níveis do design". De forma resumida, o primeiro aspecto diz respeito ao instinto imediato, a aparência; o segundo ao prazer e eficácia de uso do objeto; enquanto o último corresponde à satisfação pessoal, ao despertar de memórias (2004, p. 39). Embora descritos separadamente, para ele um projeto de design de sucesso deve atingir os três níveis.

Apesar da beleza ser um dos aspectos que merece consideração, as associações que fazemos a partir de um objeto e as memórias que podem ser evocadas a partir dele são pontos importantes. Quanto a esse aspecto, Norman ressalta que "talvez os objetos que nos são mais íntimos e diretos sejam aqueles que nós construímos, por isso a popularidade dos objetos artesanais e dos móveis feitos em casa.” (p. 48)

O livro do Museu Municipal de Penafiel (figura 12) é um caso à parte, dentro da nossa amostra e se aproxima desses objetos a que Norman se refere. Feito em coautoria por alunos do $4 .^{\circ}$ ano do ensino básico em Portugal (correspondente a nossa quinta série do ensino fundamental), surgiu a partir do sucesso de uma mostra temporária no âmbito da disciplina de inglês, abordando os "Cartões de São Valentim". As ilustrações dos cartões tiveram grande repercussão na comunidade local, a ponto de serem transformadas em produto editorial. As ilustrações serviram de base para a elaboração conjunta de cinco contos, cada um confeccionado por várias escolas da região, que foram editados pelo Museu.

19 Disponível em: http://www.museudepenafiel.com/userfiles/pdfs/livro_ummuseudeafetos.pdf. Acesso em: $12 / 08 / 2015$. 


\section{CONSIDERAÇÕES}

Após a categorização apresentada, cabe pensarmos de forma crítica nas relações que os materiais educativos podem despertar no público com o qual pretendem dialogar: as crianças. Embora perceba-se um esforço para estabelecer esse diálogo com o público, muitas vezes a abordagem parece não explorar ao máximo as possibilidades de criação de uma relação mais afetiva e duradoura.

Uma das incongruências encontradas nos materiais é o desalinhamento entre a abordagem visual e o conteúdo apresentado. Para se alcançar uma experiência significativa, é preciso pensar a ação como um todo. Explorar elementos gráficos que dialogam com o público infantil, como no caso da linguagem dos quadrinhos, busca uma aproximação com esse público. No entanto, apesar da forma adequada, o discurso carece do mesmo cuidado. Em alguns casos, o roteiro segue o padrão de um trabalho institucional, quase como uma propaganda. Em outros, apresenta regras de utilização, como em um manual de uso. Os conteúdos se distanciam de uma aproximação mais emotiva, capaz de conquistar as crianças.

A preocupação excessiva com um conteúdo didático também se mostra como um problema frequente. Ao invés de instigar a criança a criar vínculos mais afetivos com as instituições, acenando com um mundo de descobertas e novidades a ser explorado, ainda que estejam atrelados a um acervo de cunho documental e histórico, muitos materiais trazem uma abordagem focada na exposição de conteúdos, similar à linguagem utilizada nos ambientes de educação formal, que é o caso das escolas. Não queremos dizer com isso que a informação não seja relevante, mas, ao buscar construir experiências significativas, parece-nos mais importante instigar a curiosidade do que listar conhecimentos para posterior avaliação.

Ressaltamos que o conteúdo, o acervo, e a forma de se expor as informações são importantes, mas defendemos que, acima de tudo, o material deve ser capaz de transformar a experiência no/com o museu em uma atividade prazerosa, que instigue tanto a criatividade como a busca pelo conhecimento, e também o desejo de aprender, como salienta Dewey.

As publicações não são a parte mais importante no relacionamento com o visitante, se pensarmos na experiência do museu como um todo. Contudo, as publicações se mostram relevantes, ao tratar o público não apenas como um receptor, mas sim como um interlocutor. Ao possibilitar que as vozes das crianças apareçam em 
alguns materiais, por exemplo, entendemos que este efeito de personalização resulta em experiências mais memoráveis, como esclarece Norman. Em alguns materiais percebemos essa preocupação, uma vez que o público infantil é convidado não apenas a responder questões, de cunho mais educacional e menos pessoal, como também a escolher o que lhe interessa, e a produzir sentido a partir de seu repertório individual.

Talvez a grande questão seja os museus pensarem menos em preservar seus acervos como fins em si mesmos e mais em fazer uma ponte entre o conhecimento que lhes é peculiar e a experiência de vida dos visitantes. Esse pode ser o caminho para conseguirem interagir melhor com o público, sendo vistos como lugares difusores de histórias e, como tais, lugares para se ter experiências.

\section{REFERÊNCIAS}

BENJAMIN, W. Magia e técnica, arte e política: ensaios sobre literatura e história da cultura. Trad. Sergio Paulo Rouanet. São Paulo: Brasiliense, 1994.

BUCHANAN, R. Wicked Problems in Design Thinking. In: The Idea of Design. Cambridge: MIT, p. 3-20, 1995.

Interview with Professor Richard Buchanan. In: Designskolen kolding, 2013. Disponível em: http://intranet.dskd.dk/index.php?id=3469. Acesso em: 15/11/2013.

CARVALHO, C. Criança menorzinha ninguém merece... In: ROCHA, Eloisa A. C. R., KRAMER, Sonia (Eds.). Educação infantil: Enfoques em diálogo. Rio de Janeiro: Papirus, p. 295-312, 2011.

CAZELLI, S. Ciência, cultura, museus, jovens e escolas: quais as relações? Tese de doutorado, PUC-Rio, 2005.

DEWEY, J. Experiência e Educação. Trad. Anísio Teixeira. São Paulo: Ed. Nacional, 1976.

NORMAN, D. A. Emotional design: why we love (or hate) everyday things. New York: Basic Books, 2004.

SARMENTO, M. J. As culturas da infância nas encruzilhadas da $\mathbf{2}^{\mathbf{a}}$ modernidade. Instituto de Estudos da Criança da Universidade do Minho, Portugal, 2002. Disponível em: http://cedic.iec.uminho.pt/Textos_de_Trabalho/textos/encruzilhadas.pdf. Acesso em: 09/06/2014. 


\section{AS AUTORAS}

Luiza Novaes é designer e pesquisadora, com trabalhos nas áreas de design colaborativo, design como mediação, mídia interativa e comunicação visual. É professora nos cursos de Graduação e de Pós-graduação em Design da Pontifícia Universidade Católica do Rio de Janeiro - PUC-Rio, no Brasil. Tem PhD em Design pela PUC-Rio e MFA em Fotografia e Media Relacionada pela School of Visual Arts SVA, em New York, USA.

E-mail: lnovaes@puc-rio.br

Rosana Ferreira Alexandre é graduada em Desenho Industrial / Programação Visual pela Universidade Federal do Rio de Janeiro (2005) e mestre em Arte e Design para o Espaço Público pela Universidade do Porto (2009). Atualmente cursa doutorado em Design na Pontifícia Universidade Católica do Rio de Janeiro onde pesquisa a contribuição do design na ressignificação dos museus e a comunicação com o público. E-mail: rosanafalexandre@gmail.com 